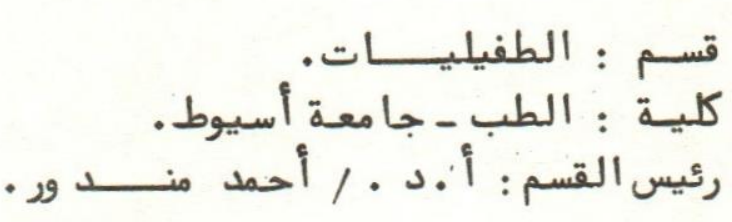

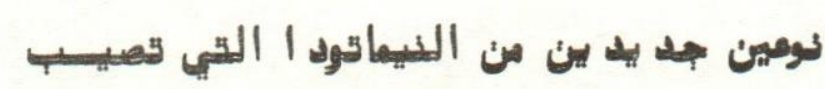

\section{العصفور المصرى باســــر د ومســـــــا}

$$
\text { أحمد منــد ور ، محمد النفـار * ليلى عمـــران }
$$

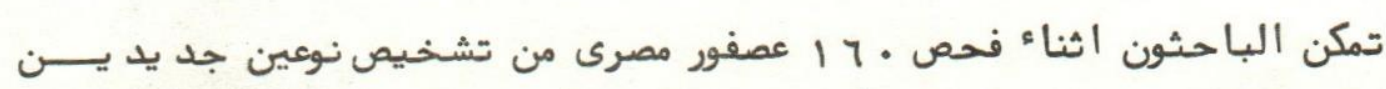

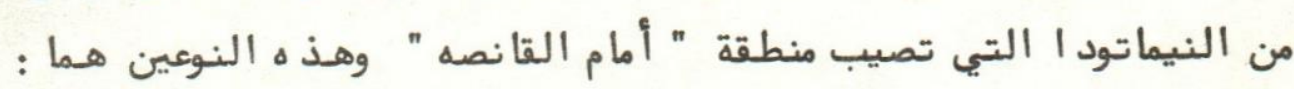
ـ أكوبريا ايجبتكا : وتوجد مقدمة هذا الطفيل مغـموره في الطبقه المخاطيه لا مام

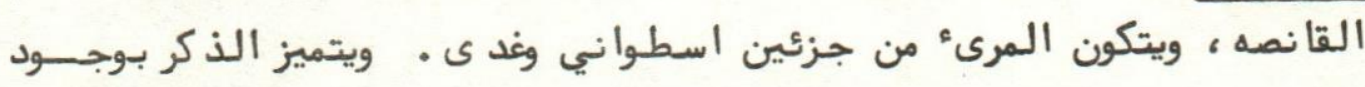

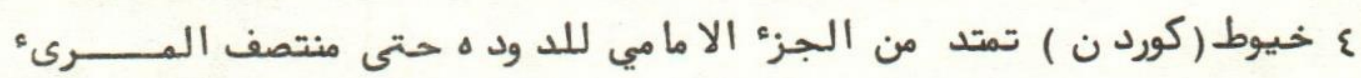

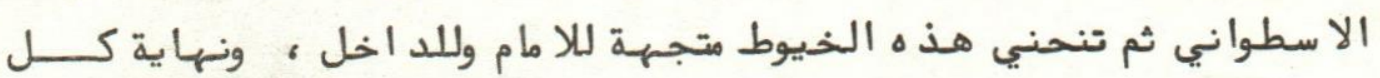

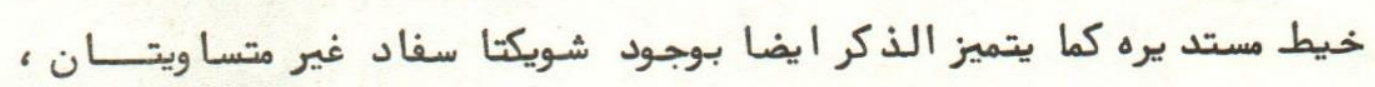

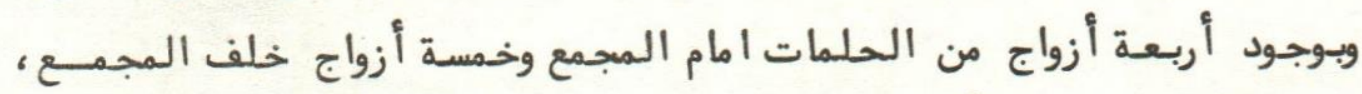

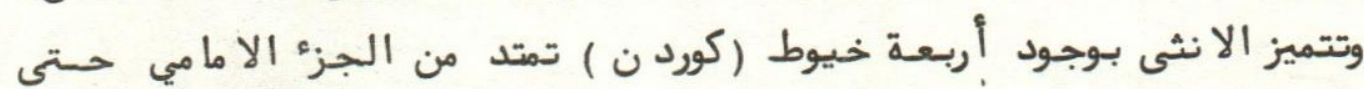

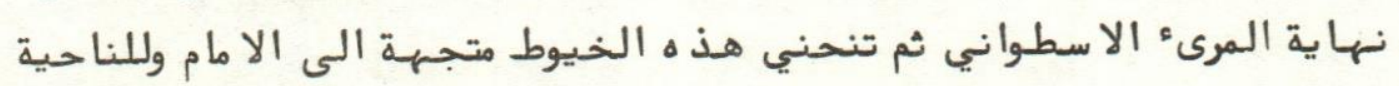

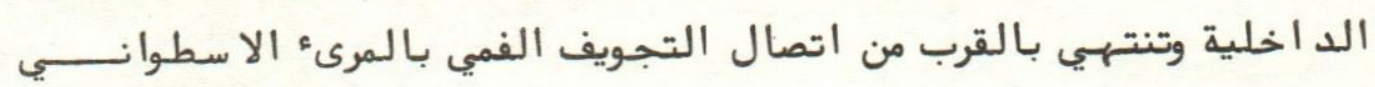

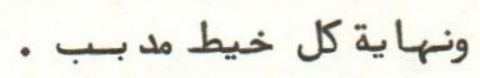

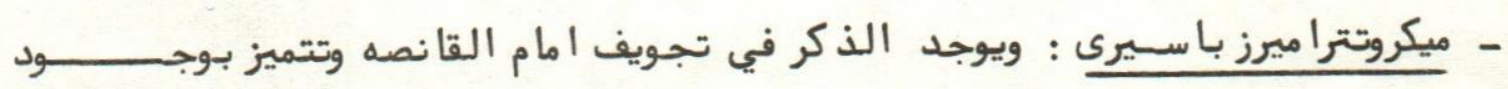

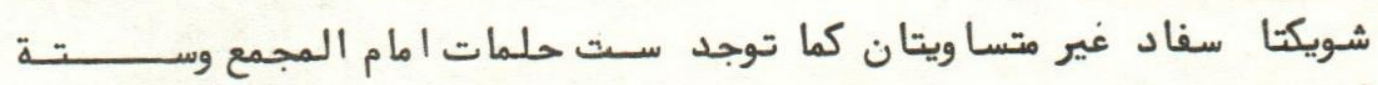

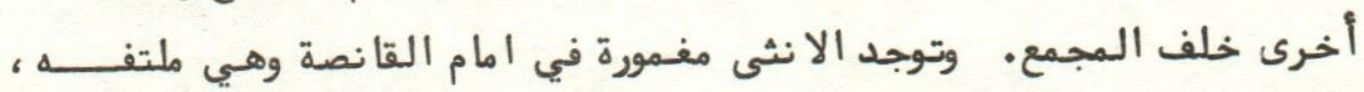
والجزء الوسطي منتفخ بينما نهايتي الد ود ة الامامي والخلفي مد ببتان .

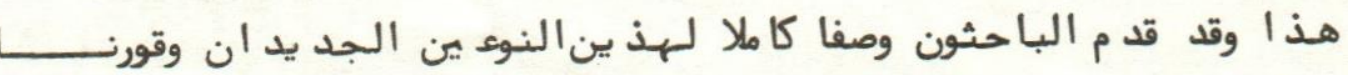

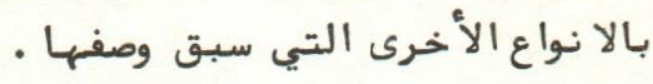
* قسم علم الحيوان_كلية العلوم جا معةأسيوط 

Dept. Of Parasitology,

Faculty of Med., Assiut University,

Head of Dept. Prof. Dr. A. Mandour.

\title{
TWO NEW PARASITIC NEMATODES INFECTING THE EGYPTIAN DOMESTIC SPARROW, PASSER DOMESTICUS
}

(With 2 Tables and 5 Figures)

\author{
By \\ A.M. MANDOUR; M.K. EL-NAFFAR and LAILA A. OMRAN \\ (Received at 22/5/1985)
}

\begin{abstract}
SUMMARY
Two new species of nematode parasites were collected from 160 sparrows, Passer domesticus captured from Assiut Province.

The two new species are : Acuaria aegyptica sp. nov. and Microtetrameres Passeri sp. nov.
\end{abstract}

\section{INTRODUCTION}

Parasites from passerines have rarely been reported from different localities of the world. However, little attention is given to the parasites of sparrows in this country. For this reason, the present work has been conducted in Assiut province.

\section{MATERIAL and METHODS}

One hundred and sixty sparrows, Passer domesticus were captured from different localities in Assiut province. They were killed $5-10$ daily to be autopsied. The alimentary canal was cut opened beginning with the crop till the cloaca. The present nematodes were found in the proventriculus. Some were found deeply embedded in the mucosa while some were found partially attached to the mucosa of the proventriculus. The worms were collected in glycerine alcohol and they were transferred to lactophenel to be examined microscopically. Portions of the infected proventriculus with the embedded worms were fixed in $10 \%$ formol saline and paraffin sections were prepared to be stained with Haematoxyline and eosin. All drawings were made by camera lucida with haematoxyline and eosin. Camera lucida drawings as well as photomicrographs were made.

\section{Order Spiruroidea \\ Family Acuaridae \\ Acuaria (Dispharynx) aegyptica sp. nov.}

This parasite is commonly found in proventriculus of the domestic sparrow in Assiut Province. About 20\% were found infected with this parasite. The anterior portions of the worms were embedded in the mucosa, thus they were only extracted with the aid of a forceps. Usually both males and females were found.

Assiut Vet. Med. J. Vol. 15, No. 30, 1986. 


\section{ANM. MANDOUR, et al.}

Male : Is whitish in colour measuring about $4.24-4.78 \mathrm{~mm}$ in length by $0.25-$ $0.36 \mathrm{~mm}$ in breadth. The poterior end of the male is coiled (Fig. $1 \mathrm{~b}$ ). At its anterior margin there are 4 pairs of papillae (Fig. 1 a), two of which being the largest measuring about 6 - 8 u. The buccal capsule is elongated measuring from $80-90 u$ in its length. Four characteristic sinuous cordons extend from the anterior end and pass posteriorly till half the length of the cylindrical oesophagus then cordon recur anteriorly and medially but not communicate with their origin (Fig. 1 a). Each cordon is $0.88-0.72 \mathrm{~mm}$ long by 13.2 - $15.2 \mathrm{u}$ wide. The terminal end of each cordon is blunt.

The oesophagus consists of two portions, a cylindrical anterior part measuring 0.52 - $0.69 \mathrm{~mm}$. by 0.072 - $0.080 \mathrm{~mm}$. while the posterior part is glandular measuring $1.49-1.54$ $\mathrm{mm}$. One testis is present at the posterior portion of the anterior half. A cloaca lies near the posterior part of the body at a distance of 292 - $306 \mathrm{u}$ from the posterior end of the body. The unequal copulatory spicules are present (Fig. 1 b), the long one measures 0.39 - $0.45 \mathrm{~mm}$ in length and it is provided with 8 - 9 spines on the dorsal side. The other spicule is short and thick " boot like " measuring $0.180-0.200 \mathrm{~mm}$ and it is provided with 5 - 6 spines on the dorsal side. The terminal end of the short spicule is spatula-like.

There are five pairs of postcloacal papillae each measurin $16.5-2.7 \mathrm{u}$ long, and four pairs of precloacal papillae of the same measurements.

Female : Is whitish in colour. It is longer and broader than the male, measuring about $7.2-8.2 \mathrm{~mm}$ in length and $0.410-0.624 \mathrm{~mm}$. in width. There are 4 pairs of lips at the anteriorar end of the body (Fig. 2 a, b), two of which being large measuring 12 $14 \mathrm{u}$.

The buccal capsule is elongated measuring $100-112 \mathrm{u}$ in length by $18-22 \mathrm{u}$ in width. It leads to the oesephagus. At junction between the buccal capsul and the oesophagus 6 - 7 teeth-like processes are found articulating with each other (Fig. 2 b). The oesophagus consists of two portions, the anterior part is cylindrical, measuring $0.83-0.88 \mathrm{~mm}$ wide. The posterior part of the oesophagus is glandular partially obscured by the uterus, and it measures $0.17-0.18 \mathrm{~mm}$ in width. There are four sinuous cordons extending from the anterior end passing postriorly till the posterior border of the cylindrical oesophagus (Fig. 2 a). The cordons recur anteriorly and medially to stop near the junction between buccal capsule and the cylindrical oesophagus. Each cordon measures about $1.23-1.36 \mathrm{~mm}$ in length by 14 - $16 \mathrm{u}$ in width (i.e., 1/2 length in male). The terminal end of the cordon is pointed. Each cordon is tube like with transverse striations (Fig. 2 b). A single ovary is situated at the anterior part of the body. It leads to the uterus which extends from the glandular oesophagus till the anus and the uterus is packed with ova (Fig. 2). The fully ambryonated ova are elliptical in shape with a thick shell (Fig. 2 b), each measuring $38-41$ u. by $23-25$ u.

The vulva is situated at a distance of $0.98-1.32 \mathrm{~mm}$. from the posterior end of the body. The tail is about $0.118-0.132 \mathrm{~mm}$ in length. It is worthy to mention that the number of females are more than males.

\section{DISCUSSION}

The morphological characters of the present parasite coincides with the general characters of family Acuaridae SEURAT, 1913, Genus Acuaria Bremser, 1811.

Assiut Vet. Med. J. Vol. 15, No. 30, 1986. 


\section{PARASITIC NEMATODES}

YAMAGUTI (1958) mentioned that fifty species of Acuaria and 20 species of Dispharynx are reported in different birds all over the world, although it is rarely recorded in sparrows and no reports in Egypt.

When the present nematode has been compared with other species of Dispharynx especially those recovered in sparrows it is found to be more or less identical with A. (Dispharynx) spiralis MOLIN, 1828. However, it differs from the latter species in many respects (Table 1).

From the above table, it is quite clear that Acuaria (Dispharynx) spiralis differs in many respects from the present material.

When the cordons of the present parasite is compared wih that of Dispharynx nasutus RUDOLPHI, 1819, a spirurid recovered from sparrows, it was found that the cordons are recurrent laterally while that in the present material are recurrent ventrally. This difference has been found of taxonomic importance by CHABAUD et al. (1959). For this reason the present parasite is not comparable with D. Nasutus GOBLE and KUTZ (1945), DUJARDIN(1845), from English sparrows respectively.

From this interpretation it is suggested that the present nematode is a new one to which we propose to name it Acuaria (Dispharynx) aegyptica since it has for the first time been reported in Egypt.

\section{Host, Passer domesticus}

Locality : Assiut, Egypt.

Type : Depostited at the Department of Parasitology, Faculty of Medicine, Assiut, University, and the department of Zoology, Faculty of Science, Assiut University.

\section{Order Spiruroidea \\ Family Microtetrameridae \\ Microtetrameres Passeri sp. nov.}

This parasite is not uncommonly found in the proventriculus of the domestic sparrow in Assiut province. About $8 \%$ were found infected with this parasite.

Male : Is whitish in colour measuring about $2.12 \div 2.34 \mathrm{~mm}$ in length and 0.08 $0.086 \mathrm{~mm}$ in breadth. The male is usually found free in the lumen of the proventriculus. The anterior end is broader than that of the female; and is provided with 6 papillage (Fig. $3 \mathrm{a}$, each measures $2-3 \mathrm{u}$. The buccal capsule is $12-15 \mathrm{u}$ in length. The oesophagus consists of a cylindrical part measuring $90-100 \mathrm{u}$. in length by $15-17 \mathrm{u}$ in breadth, and glandular lying posteriorly. One testis is situated at a distance of $0.50-0.54 \mathrm{~mm}$. from the anterior end.

There are two unequal copulatory spicules (Fig. 3 b), the larger is nearly half the total length of the worm being $1.12-1.14 \mathrm{~mm}$ but the short one is about $0.106-0.109$ $\mathrm{mm}$. Six post-cloacal papillae and 6 pre-cloacal papillae were also detected. The tail measures $0.146-0.142 \mathrm{~mm}$ long by $32-35 \mathrm{u}$ wide.

Female : Is swollen, deeply embedded in the proventriculus. From the outer surface of the proventriculus, the female looks like a haematoma. It is reddish brown in colour that it resembles a particle of red brick when dissected out. Generally, the female worm is coiled (Fig. 4 a), the middle part swollen while the anterior and posterior ends are pointed. These

Assiut Vet. Med. J. Vol. 15, No. 30, 1986. 


\section{A.M. MANDOUR, et al.}

coils were decorated with dark transvers bands. The total length of the body is about 3.6 - $4.3 \mathrm{~mm}$. At the anterior border minute spines ( 8 - 10 on each side) could be detected on high magnifications (Fig. 4 b). Also at the anterior end there are six small papillae. The buccal capsule is about $35-42 \mathrm{u}$ in length, it leads to the oesophagus which consists of a cylindrical portion measuring $0.20-0.24 \mathrm{~mm}$ long by $0.24-0.27 \mathrm{~mm}$ wide. The glandular portion measures about $0.69-0.76 \mathrm{~mm}$ long by $0.080-0.092 \mathrm{~mm}$ wide. Posterior to the buccal capsule there are 3 pairs of large papillae on the lateral sides (Fig. $4 \mathrm{c}$ ), measuring 14 - 18 u long. The cervical alae were observed on the anterior portion of the body (Fig. 4 c). The single tubular ovary leads to a coiled uterus which is filled with ova (Fig. 5 a). Usually some ova are fully embryonated.

The ova (Fig. 5 b) were mostly elliptical with one side slightly flattened. The fully embryonated ova possess differentiated plug-like structures at either poles which were not observed in immature ova. At the juction between the plug and the shell, there is a slight thickening. The vulva lies at $0.18-0.19 \mathrm{~mm}$ from the posterior end of the body. The anal opening lies just anterior to the vulva. The tail is about $0.19-0.20 \mathrm{~mm}$ long.

\section{DISCUSSION}

The morphological characters of the present parasite coincides with general characters of the family Tetrameridae, Genus Microtetrameres described by YAMAGUTI (1958). ELLIS (1969) mentioned that 14 species of Microtetrameres are reported in the Western Hemisphore Ellis (1969) concluded that the characters and measurements of the buccal capsule, and eggs are less subject to changes at the time of fixation and they are reliable criteria than other characters. On these basis he (1969) created a key to different species of female Microtetrameres from Western Hemisphere. When the present material was compared with the key of ELLIS (1969), it was found to be superficially identical with M. aquilla described by SCHELL (1953). However, the present material was found to be quite different from $\underline{M}$. aquilla in many respects (as shown in Table 2).

From this table it is clear that the parasite recovered from the golden eagle from North America is quite different from the parasite under discussion. For this reason, it is proposed to name the present parasite. Microtetrameres Passeri spp. nov.

Host : Egyptian sparrow Passer domesticus a new host.

Location : Proventriculus.

Type : Deposited in the Department of Parasitology, Faculty of Medicine, Assiut University, and in the Department of Zoology, Faculty of Science, Assiut University.

\section{REFERENCES}

Chaboud, Alain G. and Annie J. Peter (1959): Essai de classification des Nematodes acuaridae. Parasitol. humain et Comp 34, 331 - 349.

Ellis, C.J. (1969): Life history of Microtetrameres centuris Borus, 1966 (Nematode: Tetrameriadae J. parasit $55(4), 713-719$.

Schell, S.C. (1953): Four new species of Microtetrameres (Nematode: Spiruroidea) from North American birds. Trans. Amer. Micro. Soc. 72 (3), 227 - 236.

Yamaguti, S. (1958): Systema helminthum. Nematodes, Publ. Tokyo.

Assiut Vet. Med. J. Vol. 15, No. 30, 1986. 
PARASITIC NEMATODES

Table (1)

Shows the difference between Acuaria (Dispharynx) spiralis and the present material

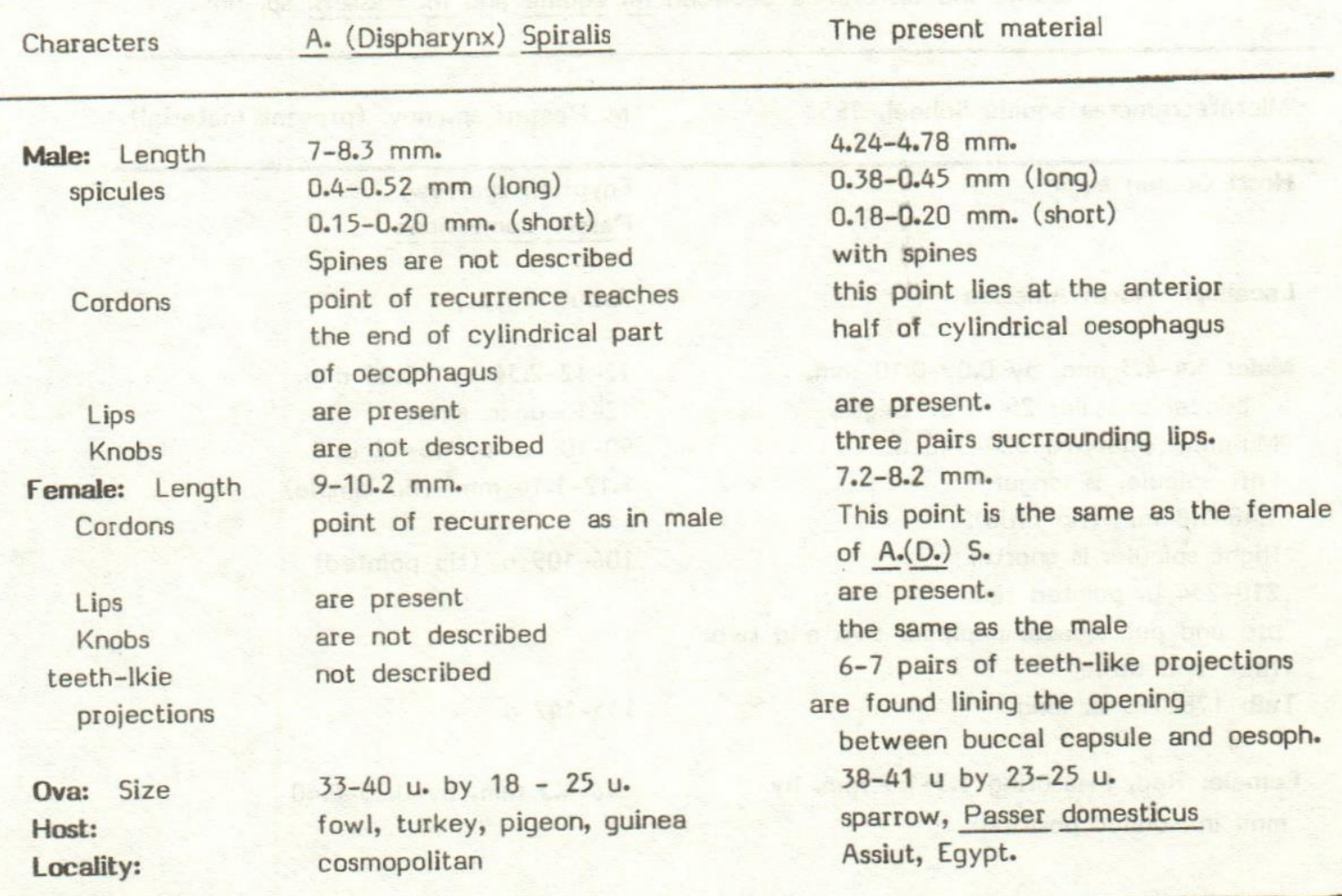

Assiut Vet. Med. J. Vol. 15, No. 30, 1986. 


\section{AM. MANDOUR, et al.}

Table (2)

Shows the difference between $\underline{M}$. aquilla and $\underline{M}$. Passeri, sp. nov.

Microtetrameres aquilla Scheel, 1953

Host: Golden eagle

Lacality: North America

Male: $3.4-4.3 \mathrm{~mm}$. by $0.09-0.10 \mathrm{~mm}$. buccal capsule: $25 \mathrm{u}$. in length.

Muscular pharynx: $324-340 u$

Left spicule, is longer

1.48-1.8 mm (tip bifid).

Right spicule: is shorter

210-234 u. pointed tip.

pre and pot cloacal papillae: two and two.

Three and three

Tail: $178-193$ u. long

Female: Red, Measuring 1.3-1.5 mm. by $\mathrm{mm}$. in coiled position.

buccal capsule: $27-28$ u. in length.

Muscular pharynx: 306-330 u. long

Glandular oesophagus: $1.34-1.39 \mathrm{~mm}$.

Vulva: $82-90$ u. anterior to anus

Anus: $113-133 \mathrm{u}$. from tip of tail

Eggs: 23-26 u. embryonated
M. Passeri sp. nov. (present material)

\section{Egyptian sparrow,}

Passer domesticus

Assiut, Egypt,

$12-12-2.34$ by $80.86 \mathrm{~mm}$.

12-15 u. in length.

90-1.00 u. by 15-17 u.

1.12-1.14 mm. (tip simple)

106-109 u. (tip pointed)

135-142 u.

$3.6-4.3 \mathrm{~mm}$. by $0.25-0.40$

35 to 42 u.

200-240 u. long.

690-760 u. long.

$65 \mathrm{u}$.

200-250 u.

47-54 by 33-37 u. and embryonated.

Assiut Vet. Med. J. Vol. 15, No. 30, 1986. 


\section{PARASITIC NEMATODES}

\section{LEGENDS}

Fig. (1): Male of Acuaria (Dispharynx) aegyptica sp. nov.
a) Anterior portion.
b) Posterior portion.

Fig. (2): Female of Acuaria (Dispharynx) aegyptica sp. nov.
a) Anterior portion.
b) Magnified anterior end.
c) Posterior portion.
d) Egg.

Fig. (3): Male of Microtetrameres passeri sp. nov.

a) Anterior portion.

Fig. (4): Femate of Microtetrameres passeri sp. nov.
a) Whole worm.
b) Magnified anterior end.
c) Anterior portion.

Assiut Vet. Med. J. Vol. 15, No. 30, 1986. 



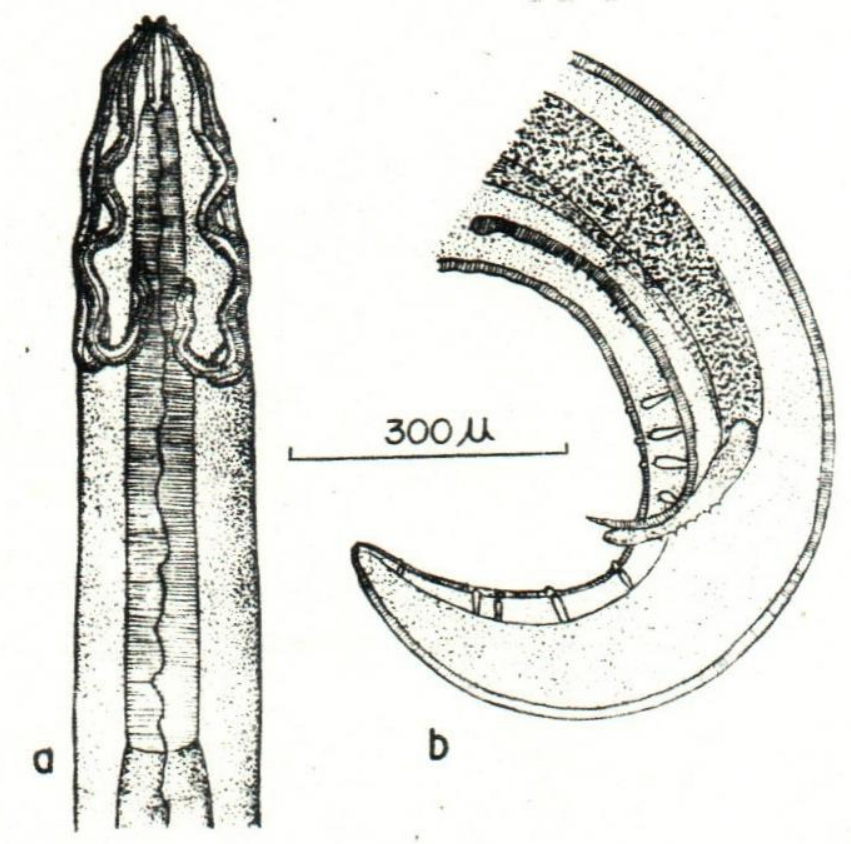

Fig. I

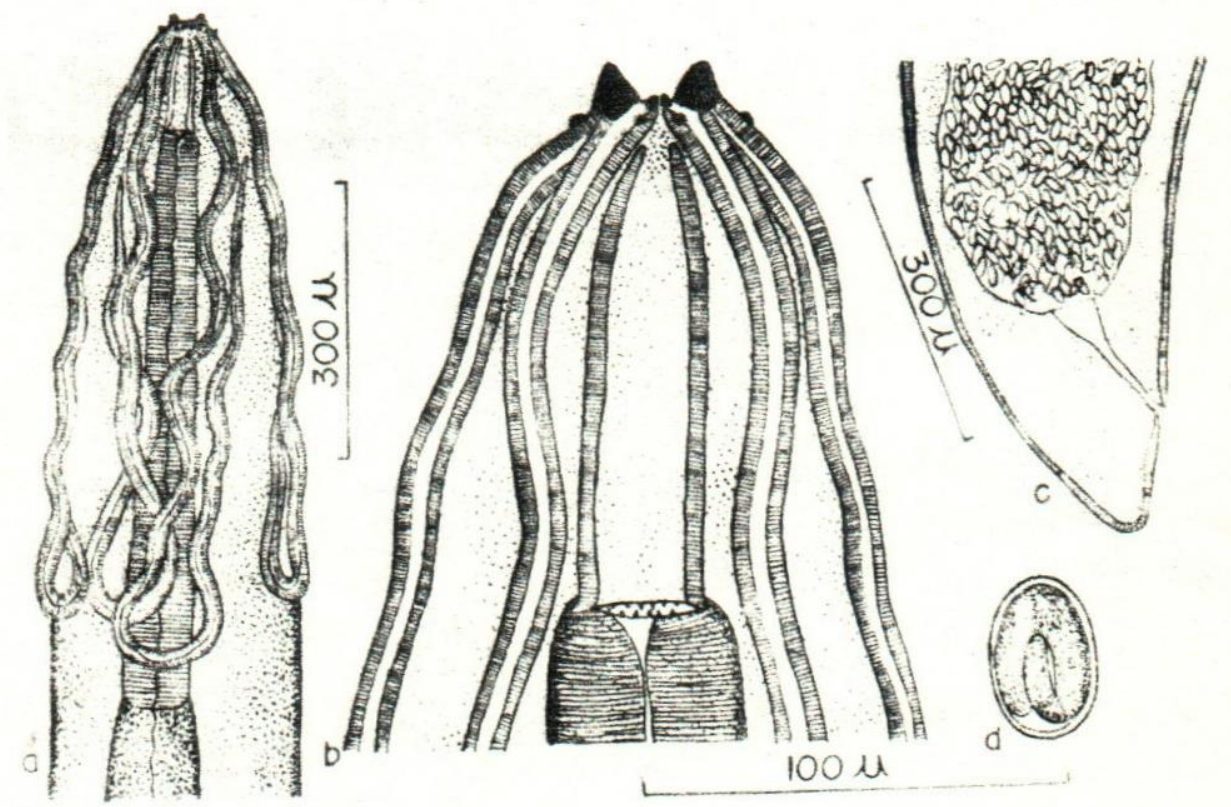

Fig. 2 


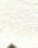
$\rightarrow$

-

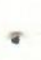




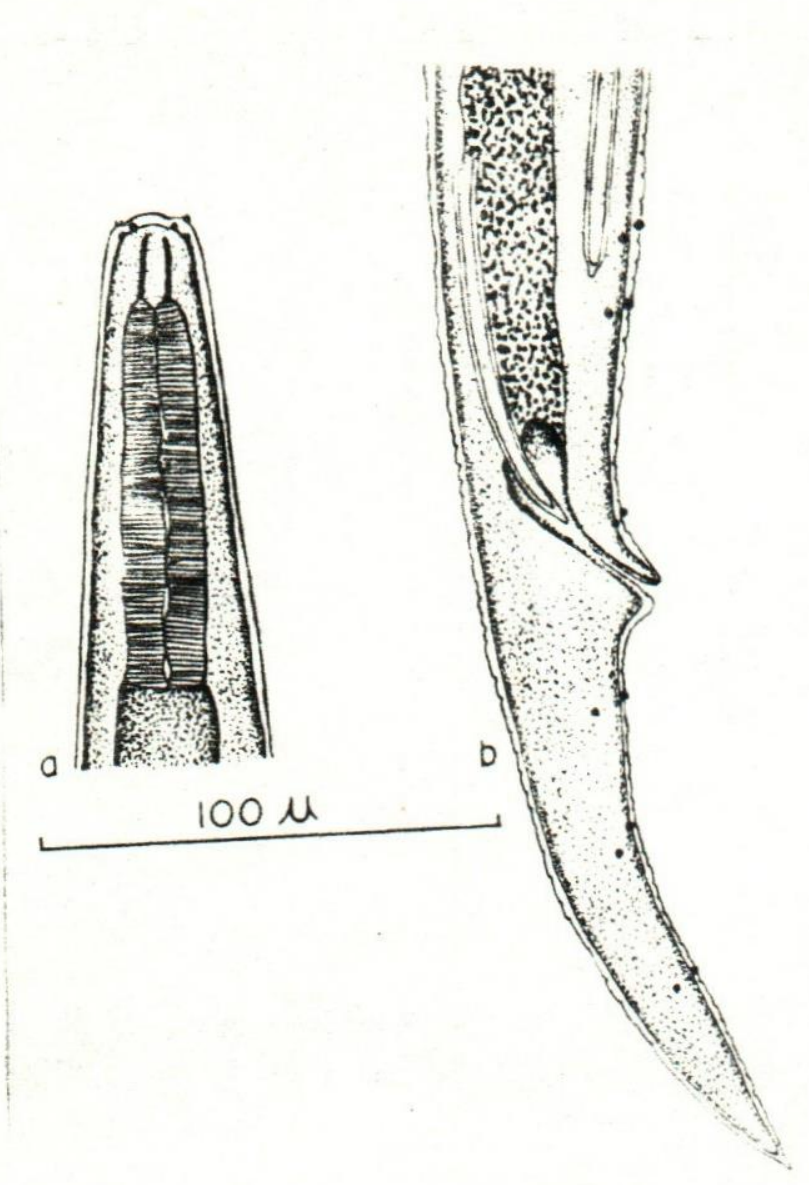

Fig. 3

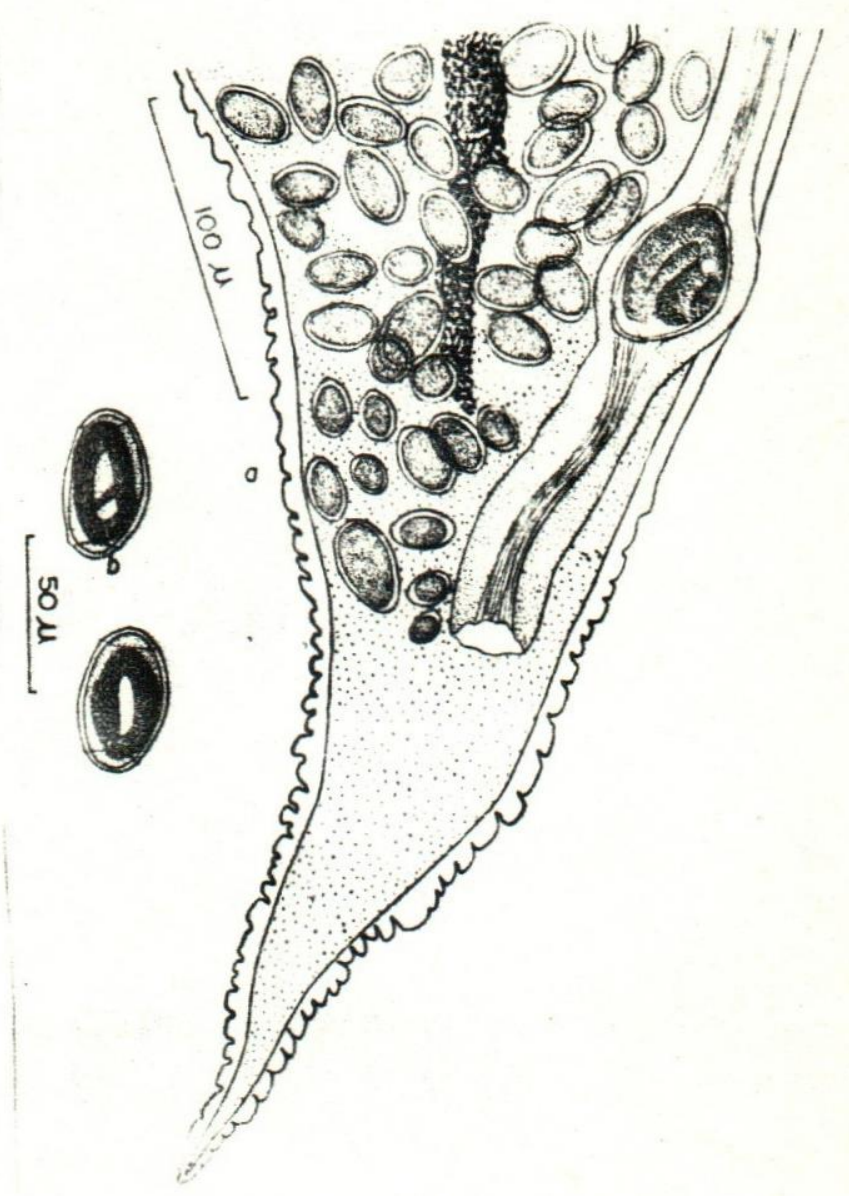

Fig. 5

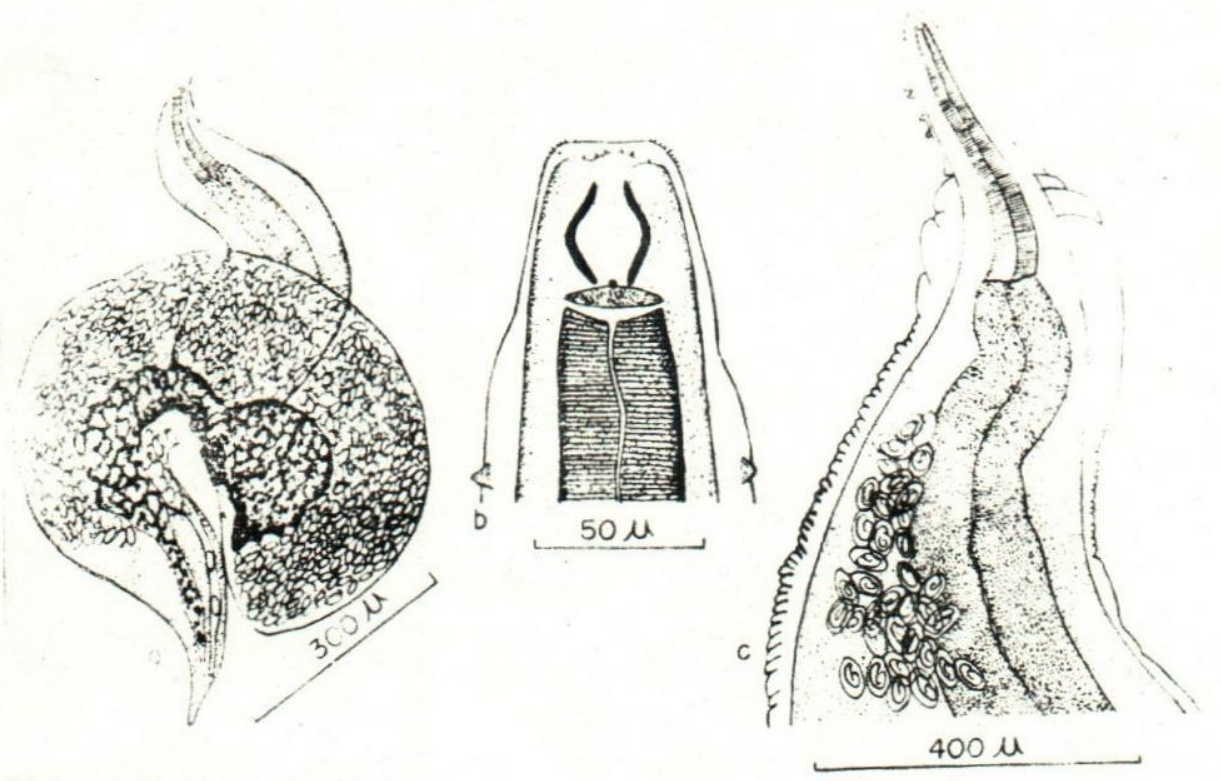

Fig. 4 
